\title{
An Explanationist Account of Genealogical Defeat
}

\author{
Daniel Z. Korman $^{1} \quad$ Dustin Locke ${ }^{2}$
}

${ }^{1}$ University of California, Santa Barbara

${ }^{2}$ Claremont McKenna College

\begin{abstract}
Sometimes, learning about the origins of a belief can make it irrational to continue to hold that belief-a phenomenon we call 'genealogical defeat'. According to explanationist accounts, genealogical defeat occurs when one learns that there is no appropriate explanatory connection between one's belief and the truth. Flatfooted versions of explanationism have been widely and rightly rejected on the grounds that they would disallow beliefs about the future and other inductively-formed beliefs. After motivating the need for some explanationist account, we raise some problems for recent versions of explanationism. Learning from their failures, we then produce and defend a more resilient explanationism.
\end{abstract}

\section{1 | INTRODUCTION}

Cases like the following suggest that acquiring certain information about the origin of one's belief can sometimes make it irrational to continue to hold that belief.

\section{NAMIBIA}

Nysha reads a book about Namibia and believes what she read. Among other things, she reads and believes that there are monarch butterflies there. She then learns that the book's author has never been to Namibia, has never read anything about Namibia, has never spoken with anyone who has been to Namibia, has never seen photos from Namibia, and so on. In short, Nysha learns that the author has had no contactdirect or mediated-with Namibia, and was just making stuff up for the purposes of publishing a book. 
Learning what she does about the origin of the book, and thus the origin of her belief, should lead Nysha to abandon that belief. As epistemologists like to say, Nysha has acquired an undercutting defeater for her belief: roughly, a piece of information that makes it (epistemically) irrational for her to continue to believe as she does for the reasons she does, but without necessarily giving her reason to believe the negation of what she believes. Since what's doing the defeating in NAMIBIA is information about the origins of Nysha's belief, we'll call this epistemic phenomenon 'genealogical defeat'.

Why, in learning what she does about the origin of her belief, has Nysha's belief been defeated? A natural answer is that her belief is defeated because she has-or at least ought to haverecognized the lack of an appropriate explanatory connection between her beliefs about Namibia and the facts about Namibia. Appropriating some terminology from David Faraci (2019), we'll call this 'the explanationist approach to genealogical defeat' (to be contrasted with the modalist approach we'll address in $\S 3$ ).

Describing the basic explanationist approach, as we have just done, is easy. Describing what counts as the 'appropriate explanatory connection' is hard. A flatfooted explanationist might endorse a principle like the following.

$\left(\mathrm{E}_{\mathrm{NAIVE}}\right)$ If $\mathrm{S}$ is not entitled to believe that her belief that $\mathrm{p}$ is explained by the fact that $\mathrm{p}$,then $\mathrm{S}$ 's belief that $\mathrm{p}$ is defeated.

This principle delivers the desired result in NAMIBIA, since Nysha recognizes — or at least ought to recognize-that her belief that there are monarchs in Namibia is not explained by the fact that there are monarchs in Namibia. But this principle is overly demanding, as is evident when one considers mundane inductive beliefs:

\section{SUNRISE}

Sonny believes that the Sun will rise tomorrow. Upon reflection, he realizes that the fact that the Sun will rise tomorrow doesn't even partly explain his believing that it will rise tomorrow.

Sonny's realization clearly doesn't jeopardize his inductive belief that the Sun will rise tomorrow. So $\mathrm{E}_{\mathrm{NAIVE}}$ cannot be right: the correct explanationist principle, whatever it might be, mustn't say that belief is defeated whenever one is not entitled to believe that the fact that $\mathrm{p}$ (itself) figures in the explanation of one's belief that p. Explanationists are well-aware of this, but they have not agreed on what principle should replace $\mathrm{E}_{\mathrm{NAIVE}} \cdot{ }^{2}$

In the literature, one can find three main explanationist strategies for accommodating inductive beliefs. Each says that genealogical defeat occurs whenever one is not entitled to believe that some specific relationship holds between the fact that $\mathrm{p}$ and those facts that explain one's belief that $\mathrm{p}$, but without requiring (as $\mathrm{E}_{\mathrm{NAIVE}}$ does) that the fact that $\mathrm{p}$ itself explain the belief. On

\footnotetext{
${ }^{1}$ Genealogical defeat has recently come to prominence in discussions of evolutionary debunking arguments in metaethics. According to these arguments, our moral beliefs are defeated by what we have learned about the origins of those beliefs, at least from the perspective of robust forms of moral realism. See Vavova (2015) for an overview. These arguments are controversial, and at the center of the controversy is a debate about the nature of genealogical defeat.

${ }^{2}$ Though see Bogardus and Perrin (forthcoming: $\$ 2$ ) for a valiant attempt to defend a "flatfooted" version of explanationism.
} 
domain-relative versions, it is enough (to be entitled to believe) that facts from the same domain as $\mathrm{p}$ explain the belief that $\mathrm{p}$. On third-factor versions, it is enough that facts that explain the belief that $\mathrm{p}$ also explain the fact that $\mathrm{p}$. On support-based versions, it is enough that relevant facts that explain one's belief that $\mathrm{p}$ logically support one's belief that $\mathrm{p}$. In what follows, we show that distinctive problems arise for each of the three approaches, and we ultimately develop and defend a refined version of support-based explanationism.

\section{2 | PRELIMINARIES}

As we said, our aim is to assess various attempts to formulate the appropriate explanatory connection at the heart of explanationist principles. But any explanationist principle will have numerous other moving parts. Is the mere absence of the connection enough to get one into epistemic trouble? Or is it some attitude (or lack thereof) concerning the presence or absence of the connection that gets one into epistemic trouble, and if so, which attitude? And what exactly is the "epistemic trouble" that one gets into? These many degrees of freedom lead to varieties of the explanationist approach that are, if not incommensurable, at least very difficult to compare.

For purposes of comparing the core insights of the variety of explanationist proposals, we will put all the proposals we wish to evaluate in a certain standard form-namely,

(E) If $S$ is not entitled to believe that a certain explanatory relation obtains withrespect to her belief that $\mathbf{p}$, then S's belief that $\mathrm{p}$ is defeated.

To obtain a specific version of explanationism, the portion in bold is replaced with some condition specifying the sought-after explanatory connection. One example is the flatfooted principle mentioned just above:

\section{( $E_{\text {NAIVE }}$ ) If $S$ is not entitled to believe that her belief that $\mathbf{p}$ is explained by the fact thatp, then S's belief that $\mathrm{p}$ is defeated.}

Before proceeding to consider more plausible versions of(E), we'll need to make a few preliminary remarks about how we understand (E) and why we have formulated it in the way we have. ${ }^{3}$

First, we have formulated (E) in a way that is friendly to both "internalist" and "externalist" approaches in epistemology. (E) is internalist-friendly because it does not say that defeat is generated by a mere absence of the appropriate explanatory connection. Rather, it says that if one is in a certain epistemic position with respect to whether that connection obtains, then defeat ensues. (E) is externalist-friendly because, while externalists might insist that justification requires the presence of the connection, they will presumably agree that one's being in a certain epistemic position with respect to whether it obtains (e.g., justifiably believing-even mistakenly-that it fails to obtain) suffices for defeat. ${ }^{4}$

Second, for someone to be entitled to believe something is for it to be rationally permissible for them to believe it. One way to be entitled to believe that $\mathrm{p}$ - that is, one way for it to be rationally

\footnotetext{
${ }^{3}$ One issue we will not address herein is whether explanationist principles are self-defeating, insofar as our beliefs about such epistemic principles (allegedly) cannot stand in explanatory relations to the associated epistemic facts. See Pust (2001) and Korman (2019a: §5.2) for discussion.

${ }^{4}$ Cf. Bergmann (2005).
} 
permissible to believe that $\mathrm{p}$-is to have sufficient evidence for $\mathrm{p}$. But we do not assume that evidence is the only path to entitlement. Indeed, there may be some things one is entitled to believe without evidence. Also, in keeping with our neutrality with respect to the internalism/externalism debate, we do not make any assumptions about whether entitlement is in part a matter of the state of the world "outside one's head" or "beyond one's awareness".

Third, (E) does not say that all those who in fact withhold belief in the relevant explanatory connection have their beliefs defeated. Rather, (E) says that when one ought to withhold belief in the explanatory connection-that is, when one isn't entitled to believe in the explanatory connection-one's belief is defeated. (E) is formulated this way because one might irrationally withhold belief in the explanatory connection, and we don't want the principle to say in those cases that one's belief is defeated; what one ought to do in such cases is to stop withholding belief in the explanatory connection. ${ }^{5}$

Fourth, when we say that a belief has been defeated, we mean that one has acquired a defeater for the belief given its current grounds. Having an undercutting defeater does not necessarily mean that one cannot rationally continue believing, for one might have at one's disposal some other good and undefeated grounds for believing. In cases where one has no other such grounds, however, having an undercutting defeater will render one unable (in one's current epistemic state) to rationally retain the belief.

Fifth, (E) is formulated in such a way as to remain neutral on when one ought to withhold belief in an explanatory connection. When Nysha learns what she does about the book's origin, she ought to withhold from believing that there is any explanatory connection between the facts about Namibia and what the book says about Namibia. But it's not the job of an explanatory constraint to explain why Nysha should believe what she hears about the origins of the book, rather than disregarding what she heard and standing by her belief in an explanatory connection. Rather, (E)'s job is to tell us when and why, given that one ought to withhold from believing that a certain explanatory connection obtains, defeat ensues.

Sixth, we will always understand 'explain' to include cases of partial explanation, and we don't necessarily intend for this to be restricted to causal explanations. ${ }^{6}$ Also, in an effort to reduce the number of moving parts in this paper, we assume that explanation is a relation between facts. Accordingly, talk about what explains a belief should be understood as shorthand for talking about what explains the fact that one has that belief. Those who take explanation to be a relation between events can translate what we say below into their preferred terms.

Finally, a word of warning. There is a certain kind of case-one that will be important belowwhere one must be extremely careful in how one applies a principle of defeat. The cases we have in mind are those in which one's entitlement to believe in the relevant connection between one's belief that $\mathrm{p}$ and the associated fact is closely tied to one's entitlement to believe $\mathrm{p}$ itself.

As an illustration, let $\mathrm{C}$ be the proposition that that there is a Creator of All Things, and let's suppose a certain believer in $\mathrm{C}$ has just learned that her belief in $\mathrm{C}$ is a by-product of some evolutionary adaptation. Our believer now wonders whether this new piece of knowledge undermines her entitlement to believe that there is an explanatory connection between her belief in $\mathrm{C}$ and the truth of C. Let's suppose she attempts to assure herself that she is still entitled to believe in such a connection: after all, she reasons to herself, there is a Creator of All Things, and both her belief

\footnotetext{
${ }^{5}$ Cf. Pryor (2004: §5) on rational obstruction.
}

${ }^{6}$ In particular, we wish to make room for metaphysical explanations, of the sort appealed to by Enoch (2010), Bengson (2015), and Lutz (2020: 299-300). See also Harman (1973: 130-1) on allowing noncausal explanations in order to accommodate beliefs about universal generalizations. 
in $\mathrm{p}$ and the evolutionary processes responsible for it (being among All Things) are explained by there being a Creator of All Things.

At first glance, it may seem in some sense epistemically off-limits to invoke the contested claim that there is a Creator of All Things in assessing whether the needed explanatory connection obtains. Such a response may seem to "beg the question". In our view, however, there is nothing wrong with reasoning in this way. To insist that one may not appeal to $\mathrm{p}$ in assessing whether the relevant connection obtains is simply to assume that one's belief that $\mathrm{p}$ has been defeated. But it is the job of the principle in question to deliver this result. And the principle delivers this result only if it is plausible that, even granting entitlement to believe that $p$, and therefore to use $\mathrm{p}$ as a premise in one's reasoning, one is still not entitled, in light of what one has learned about the origin of one's belief, to believe that the relevant connection obtains. It is only at this point that the principle kicks in to imply that one's belief that $\mathrm{p}$ has been defeated and that one may not rely on it. ${ }^{7}$

\section{3 | MODALISM AND ITS LIMITS}

The road to a viable form of explanationism is not an easy one. In working out the details of the correct explanationist approach, we must carefully work our way through lesser versions, demonstrating their shortcomings in order to highlight the virtues of the version we ultimately defend. Accordingly, before beginning that journey, we wish to address the concern that explanationists are barking up the wrong tree. While explanatory revelations surely do sometimes defeat, one might suspect it's not the explanatory revelation per se that is doing the defeating, but rather some other revelation that comes, so to speak, in the wake of the explanatory revelation. Along these lines, some maintain that what does the defeating in cases of genealogical defeat is not that we learn that there is no appropriate explanatory connection between our belief and the truth, but that we learn that there isn't an appropriate modal connection between the belief and the truth. ${ }^{8}$

Just as the explanationist faces the challenge of spelling out the "appropriate explanatory connection", the envisaged modalist approach faces the challenge of spelling out the "appropriate modal connection". One obvious contender is safety, where one's belief in p is safe just in case one couldn't easily have been mistaken about whether p. Framed as an account of genealogical defeat, we get

$\left(\mathrm{M}_{\mathrm{SAFE}}\right)$ If $\mathrm{S}$ is not entitled to believe that her belief that $\mathbf{p}$ is safe, then $\mathrm{S}$ 's belief that $\mathrm{p}$ isdefeated.

$\mathrm{M}_{\text {SAFE }}$ captures cases of genealogical defeat like NAMIBIA: Nysha learns that even if her beliefs about Namibia happen to be true, she easily could have ended up with mistaken beliefs, and that, the idea goes, is why her Namibia beliefs are defeated. Moreover, unlike $\mathrm{E}_{\mathrm{NAIVE}}, \mathrm{M}_{\mathrm{SAFE}}$ has no trouble with SUNRISE. There's no reason for Sonny to think that he could easily have been mistaken about whether the Sun will rise tomorrow. He believes in all nearby worlds that it will rise, and it does rise in all nearby worlds. So he's correct in all nearby worlds about whether the Sun will rise tomorrow. The belief is safe, and he is entitled to believe that it's safe.

\footnotetext{
${ }^{7}$ See our (2020: §4) for more on charges of question-begging in the literature on moral debunking arguments.

${ }^{8}$ Cf. Bedke (2009, 2014), Clarke-Doane (2015, 2016, 2020), Braddock (2017), Warren (2017), Clarke-Doane and Baras (2021), and Topey (forthcoming).
} 
However, modalism has problems of its own. In particular, it fails to capture cases of genealogical defeat involving propositions with a high degree of "modal stability", in which the appropriate modal connection is too easy to come by. ${ }^{9}$ We briefly sketch one such case here. We hasten to add that our aim in presenting the case is not to refute modalism, but rather to dispel the idea that, where the simple version of explanationism, $\mathrm{E}_{\mathrm{NAIVE}}$, fails, some simple version of modalism might succeed.

For the sake of concreteness, we'll illustrate this point specifically with respect to $\mathrm{M}_{\mathrm{SAFE}}$, but similar arguments put pressure on other modalist proposals (e.g., ones based on sensitivity rather than safety). Consider the following case.

\section{FERMAT}

Fred believes that Fermat's Last Theorem (FLT) is true. When asked why he believes it, Fred says that he remembers hearing from a mathematician friend that it has been proven. Later, however, Fred learns that he heard this, not from a mathematician, but rather from a member of the Fermat Society, which (he learns) consists of descendants of Fermat, with no interest in mathematics or knowledge of whether a proof of FLT exists, but who-in an attempt to profit off of the good reputation of this famous conjecture-have been telling as many people as they can that FLT has been proven. Fred also learns that he has been specifically targeted by the Fermat Society (who always get their mark) because he has a reputation for trying to impress people with mathematical trivia.

Learning what he does about the origin of his belief in FLT defeats Fred's belief. Yet the proponent of $\mathrm{M}_{\mathrm{SAFE}}$ has no explanation of why.

According to the proponent of $\mathrm{M}_{\mathrm{SAFE}}$, genealogical defeat occurs when and because what one learns about the origin of one's belief undermines one's entitlement to believe that the belief in question is safe. But from Fred's perspective, it seems that his belief in FLT is safe. First, it seems to him that since FLT is a mathematical truth, and since mathematical truths are noncontingent, FLT couldn't easily have been false. Second, after learning what he does about the origin of his belief-in particular, about the Fermat Society's mission-Fred will also believe that it couldn't easily have been the case that he didn't come to believe FLT. ${ }^{10}$ Putting these two things together, we get the result that, from Fred's perspective, it seems both that (i) in all nearby possible worlds, FLT is true, and (ii) in all nearby worlds, he believes it is true, and thus (iii) he could not easily have been wrong about whether FLT was true. In other words, from Fred's perspective, it seems that his belief is safe.

When we say that 'from Fred's perspective, it seems that his belief in FLT is safe', we mean that, as long as Fred still believes FLT, it will seem to him that his belief in FLT is safe. But shouldn't Fred stop believing FLT? Indeed, he should. The problem is that the modalist has no account of

\footnotetext{
${ }^{9}$ For discussion, see Lutz (2018: §3.3.2), Faraci (2019: §5), Berry (2020), Korman and Locke (2020: §§6-7), and Clarke-Doane and Baras (2021).

${ }^{10}$ Couldn't the Society member have easily (i.e., effortlessly) told Fred that FLT is false (in which case Fred would have mistakenly believed it's false)? Sure, but given her aims and objectives, this is not something that easily could have happened. It is this latter notion of what easily could have happened, and not the former notion of what one's informant could effortlessly have done, that's relevant to assessing whether a belief is safe (lest virtually all testimonial beliefs come out as unsafe).
} 
why Fred should stop believing FLT. The modalist cannot account for this case by simply insisting that Fred ought to stop believing FLT, and that once he does he will recognize that his belief in FLT is not safe. Such an "account" would simply take for granted-without any explanation-that Fred should stop believing FLT (recall our warning at the end of §2). An account of why Fred's belief in FLT is defeated that simply begins with the assumption that Fred should stop believing FLT is no account at all.

Modalists may feel that we have been unfair to them. They may wish to fortify their account by availing themselves of a more nuanced conception of safety, or by resting the account on some other modal connection, or by adding various bells and whistles. ${ }^{11}$ We do not mean to be dismissive of these efforts. We ask only that explanationists be afforded the same opportunity to develop a nuanced version of their view, adding clauses where appropriate, drawing subtle distinctions where needed, and so on. In our view, the dispute between modalists and explanationists cannot be resolved any other way: we must compare the best versions of each, and to do so we must identify the best version of explanationism.

\section{4 | DOMAINS}

Elsewhere (2020: §8), we proposed an explanationist principle meant to be an improvement on $\mathrm{E}_{\mathrm{NAIVE}}$. The idea was that what's relevant is not whether the fact that $\mathrm{p}$ itself explains the belief that $\mathrm{p}$, as $\mathrm{E}_{\mathrm{NAIVE}}$ says, but whether facts "from the same domain as p" explain the belief that $\mathrm{p}$. More precisely,

\section{( $\mathrm{E}_{\text {DomAIN }}$ ) If $\mathrm{S}$ is not entitled to believe that her belief that $\mathbf{p}$ is explained by somefact from} the domain to which $\mathbf{p}$ belongs, then S's belief that $\mathrm{p}$ is defeated.

At first glance, $\mathrm{E}_{\text {DomaIn }}$ seems just right. It would seem to accommodate SUNRISE. The fact that the Sun rises tomorrow is a fact about sunrises, and facts from the domain of sunrise facts-for instance the fact that the Sun rose yesterday and the day before-do explain Sonny's belief that the Sun will rise tomorrow. Additionally, it seems well-equipped to capture straightforward cases of genealogical defeat like NAMIBIA. Nysha recognizes that neither facts about the monarchs in Namibia nor any other facts about Namibia have any role to play in explaining why the book says that there are monarchs in Namibia and, thus, no role in explaining why she believes that there are monarchs in Namibia.

On closer inspection, however, it is far from clear what $\mathrm{E}_{\text {DomaIN }}$ does or doesn't say about these cases. ${ }^{12}$ After all, any given fact is bound to belong to multiple domains, meaning that no one domain is the domain to which it belongs. Must S's belief that $\mathrm{p}$ be explained by facts belonging to all domains to which the fact that $\mathrm{p}$ belongs, or is it sufficient that it be explained by facts

\footnotetext{
${ }^{11}$ Clarke-Doane and Baras (2021: 164), for instance, will insist (among other things) upon a domain-relativized understanding of safety, on which S's belief that $\mathrm{p}$ is safe iff $\mathrm{S}$ could not have easily had false beliefs similar to $\mathrm{p}$ using the method that $\mathrm{S}$ actually used to determine whether or not $\mathrm{p}$. Whether this handles the FERMAT case depends on how we individuate Fred's "method". Is it believing things on testimony? Believing the members of the Fermat Society? Believing people with ulterior motives? In other words, as Clarke-Doane and Baras themselves acknowledge, they face a version of the generality problem-which, as they rightly observe, is a problem for most everyone.
}

${ }^{12}$ Cf. Killoren (2021). 
belonging to some domain to which the fact that $\mathrm{p}$ belongs? This gives us two versions of $\mathrm{E}_{\text {DomaIN }}$, each of which has serious problems.

( $E_{\text {ONEDomain }}$ ) If there is even one of p's domains $\mathbf{D}$ such that $\mathrm{S}$ is not entitled to believethat her belief that $\mathrm{p}$ is explained by facts from $\mathrm{D}$, then $\mathrm{S}$ 's belief that $\mathrm{p}$ is defeated.

( $E_{\text {EAchDomain }}$ ) If for each of p's domains $D, S$ is not entitled to believe that herbelief that $p$ is explained by facts from $\mathrm{D}$, then S's belief that $\mathrm{p}$ is defeated.

$\mathrm{E}_{\text {ONEDomain }}$ is too demanding. In addition to being about sunrises, Sonny's belief is about tomorrow and about future sunrises, and no facts about tomorrow or about future sunrises have any role to play in explaining his current beliefs. So E belief that the Sun will rise tomorrow is defeated. $\mathrm{E}_{\text {ONEDomain }}$ will also have trouble with other sorts of inferential beliefs. For instance, take your belief that Biden is president or all aliens are green, which you deduced from your belief that Biden is president. E implies that this disjunctive belief is defeated since you know it isn't explained by any facts about aliens. $^{13}$

$\mathrm{E}_{\text {EAchDomaIN }}$, on the other hand, is insufficiently demanding. Nysha knows that the book is a fictional account of the actual country of Namibia and, having read her Kripke, knows that there must be a causal chain leading from the author's use of 'Namibia' to a baptismal event involving Namibia itself. ${ }^{14}$ Thus, a fact about Namibia does enter into the complete explanation of her belief that there are monarchs in Namibia, and the domain of facts about Namibia is one of the domains to which the fact that there are monarchs in Namibia belongs. Since Nysha knows this, or is at least entitled to believe it, $\mathrm{E}_{\text {EACHDomain }}$ fails to deliver a verdict of defeat in NAMIBIA.

Perhaps there is some way to steer between the horns of this dilemma by identifying a privileged domain (or set of domains) to which a given fact belongs. However, there seems to be no principled way of doing so. For example, which of the many domains to which the fact that two plus two equals four belongs is privileged: the domain of mathematics, number theory, or elementary arithmetic? We see no principled way of deciding. ${ }^{15}$ In any case, we leave this as an exercise for readers more friendly to $\mathrm{E}_{\text {DomaIN }}$. We will move on to what we take to be a more promising approach.

\section{5 | THIRD FACTORS}

Another natural suggestion is to allow for cases in which one's belief that $\mathrm{p}$ is explanatorily connected to the fact that $\mathrm{p}$ via some common explanation, whereby a "third factor" explains both the belief and the associated fact. Indeed, this was precisely Alvin Goldman's (1967) strategy when developing his causal theory of knowledge, and it figures prominently in David Enoch's (2010) formulation of - and response to-moral debunking arguments. Framed as a principle of defeat, the approach can be formulated as follows.

\footnotetext{
${ }^{13}$ Thanks to Seyed Yarandi for helpful discussion here.

${ }^{14}$ Even if 'Namibia' turns out to have been introduced by way of a reference-fixing description, there's still a fact about Namibia in the explanatory chain, namely the fact that Namibia satisfies that description.

${ }^{15}$ Thanks to an anonymous referee for bringing this point to our attention.
} 


\section{$\left(\mathrm{E}_{\text {ThIRDFACTOR }}\right)$ If $\mathrm{S}$ is not entitled to believe that either (i) the fact that p explains S'sbelief that $p$ or (ii) there is a third factor that explains both the factthat $p$ and S's belief that $\mathbf{p}$, then S's belief that $\mathrm{p}$ is defeated.}

This accommodates SUNRISE, insofar as certain facts about the past-e.g., about the earlier positions and momenta of the Sun and the Earth-are poised to explain both what will happen and our beliefs about what will happen. ${ }^{16}$

What about NAMIBIA? At first glance, it seems that $\mathrm{E}_{\text {THIRDFACTOR }}$ straightforwardly delivers the desired verdict that Nysha's belief has been defeated. However, to get this result, $\mathrm{E}_{\text {THIRDFACtoR }}$ must be handled with care. First, we must somehow disallow cheap conjunctive explanations. For if we are allowed to simply conjoin that which explains Y with that which explains $Z$ to get a thirdfactor explanation of both $\mathrm{Y}$ and $\mathrm{Z}$, then $\mathrm{E}_{\text {THIRDFACTOR }}$ is in trouble: there will be essentially no cases where it implies defeat. ${ }^{17}$ Second, we must somehow disallow cheap cosmological explanations. Suppose, for example, that Nysha rationally believes that everything in the universe started with a bang-a Big Bang, to be exact. In that case, it will seem, from her perspective, that there is a fact that figures in the explanation of both her belief that there are monarchs in Namibia and the fact that there are monarchs in Namibia-namely, the fact that there was a Big Bang. ${ }^{18}$

Perhaps proponents of the third-factorist approach can find a way out of these problems by appealing to some principled restriction on acceptable third-factor explanations. ${ }^{19}$ Even still, $\mathrm{E}_{\text {THIRDFACTOR }}$ mishandles straightforward cases of genealogical defeat like the following.

\section{Cloud CHAMBER}

Jack, a physics enthusiast, has a more or less automatic tendency to believe, upon finding out that a proton has gone through a cloud chamber, that a certain kind of streak has appeared in the chamber. Jack has just learned from a reliable source that a proton has just been fired through cloud chamber $\mathrm{C}$. Without looking at chamber $\mathrm{C}$, he spontaneously forms the belief that there is a streak in C. However, he also learns that this proton-to-streak disposition was implanted in him by a mad neuroscientist who knows nothing about physics but simply likes the sound of 'proton' and 'streak'. ${ }^{0}$

What Jack learns about the neuroscientist clearly defeats his belief that there is a streak in C. However, by Jack's lights, the fact that a proton was fired through $\mathrm{C}$ serves as a third factor,

\footnotetext{
${ }^{16}$ Cf. Setiya (2012: ch.3) and Livengood and Korman (2020) on appealing to laws of nature as a third factor.

17 "Essentially", because there are conceivable cases in which nothing explains one's belief that p.

${ }^{18}$ Cf. Lutz (2020: 298).

${ }^{19}$ See Faraci (2019: §3) on the first problem. As for the second, one might be tempted to require (à la Goldman 1967) that the believer be able to "reconstruct" the relevant explanatory chains. But this won't do, since the NAMIBIA case can easily be supplemented in such a way that a supernaturally intelligent Nysha is able to reconstruct an explanatory chain connecting both her belief and the fact to the Big Bang. A better approach, we suggest, would be to appeal to the notion of a 'contrastive explanation' (Lipton 1990), with the idea that, e.g., the formation of the Earth would no better explain the fact that there are monarchs in Namibia as it would the fact that there are not monarchs in Namibia. We don't know if such a proposal could be worked out in plausible detail. In any case, we leave this as a project for those more sympathetic to the third-factorist approach.

${ }^{20}$ Adapted from our (2020: §8).
} 
explaining both the fact that there is a streak in $\mathrm{C}$ and his belief that there is a streak in C. Relying on his antecedent proton beliefs, Jack can reason his way to that third-factor explanation, and $\mathrm{E}_{\text {THIRDFACTOR }}$ provides no account of why he is not entitled to do so. Accordingly, $\mathrm{E}_{\text {ThIRDFACTOR }}$ fails to deliver a verdict of defeat in CLOUD CHAMBER; Jack's belief that there is a streak in C remains in good standing as far as $\mathrm{E}_{\text {THIRDFACTOR }}$ is concerned.

Perhaps there are ways out of these troubles for proponents of the third-factor approach. We will leave that to them to figure out, and we will turn, at last, to what is in our view the most promising form of explanationism.

\section{6 | SUPPORT}

What we call support-based explanationism looks, not as $\mathrm{E}_{\text {DomaIn }}$ does, at whether the facts that explain the belief that $\mathrm{p}$ include facts from the same domain as $\mathrm{p}$, and not, as $\mathrm{E}_{\text {THIRDFActoR }}$ does, at whether the facts that explain the belief that $\mathrm{p}$ include or explain the fact that $\mathrm{p}$, but at whether the facts that explain the belief that $\mathrm{p}$ logically support the belief that $\mathrm{p} .{ }^{21}$ When the facts that explain the belief that $\mathrm{p}$ include the fact that $\mathrm{p}$, the facts that explain the belief that $\mathrm{p}$ deductively support the belief that $\mathrm{p}$. But that is not the only way that a set of facts may support a belief: they may also inductively support a belief.

Putting the notion of support to work in an explanationist principle, we get:

\section{( $E_{\text {SUPPORT }}$ ) If $S$ is not entitled to believe that the facts that explain her belief that psupport her belief that $\mathbf{p}$, then S's belief that $\mathrm{p}$ is defeated. ${ }^{22}$}

This helps with many of the problems above. In SUNRISE, the belief that the Sun will rise tomorrow is inductively supported by the facts that explain it, namely facts about past sunrises, and Sonny is entitled to believe that it is. Your belief that Biden is president or aliens are green is deductively supported by a fact that explains the belief, namely the fact that Biden is president, and you are entitled to believe that it is. So both beliefs are rightly in good standing as far as $\mathrm{E}_{\mathrm{SUPPORT}}$ is concerned. By contrast, in NAMIBIA, although Nysha is entitled to believe that some facts about Namibia are in the explanatory history of the book (for the Kripkean reasons mentioned in §5), those particular facts don't, as far as Nysha is entitled to believe, support her specific belief that there are monarchs in Namibia. So $\mathrm{E}_{\mathrm{SUPPORT}}$ rightly implies that her belief is defeated.

Some care must be taken in how we understand the term 'support'. To see why, let's return to Cloud Chamber. Consider the following two propositions.

(Proton) There is a proton in cloud chamber C.

(Streak) There is a streak in cloud chamber C.

Does (Proton) support (Streak)? In one sense, it does: anyone who knows that protons leave streaks in cloud chambers is within their epistemic rights to infer (Streak) from (Proton). If the notion of 'support' is interpreted such that (Proton) therefore supports (Streak), then by Jack's lights,

\footnotetext{
${ }^{21}$ Here we treat 'supports' as denoting a relation that can obtain between facts and beliefs. Those who wish to reserve 'supports' for a relation between propositions can translate claims of the form the fact that p supports the belief that $q$ into claims of the form the proposition that $p$ supports the proposition that $q$.

${ }^{22}$ Cf. Lutz (2018: §2) and Korman (2019b: §8).
} 
the fact expressed by (Proton) does both explain and support his believing (Streak), and $\mathrm{E}_{\mathrm{SuPPORT}}$ therefore fails to deliver a verdict of defeat.

We think the above line of reasoning interprets the notion of 'support' too loosely. From the fact that [someone may reasonably infer from $x$ is $A$ to $x$ is $B$ ], it does not follow that $[x$ is $A$ supports $x$ is $B]$. Rather, more typically, what supports $x$ is $B$ is $x$ is $A$ together with some proposition "linking" $A s$ to Bs. This appears to be so in the case at hand. (Proton) does not, on its own, support (Streak); rather, it does so only together with the linking proposition

(Proton-Streak) Protons leave streaks in cloud chambers.

Indeed, even when one is justified in endorsing the proposition linking $A s$ to $B s$, it does not follow that $x$ is $A$ supports-in the sense intended here-that $x$ is $B$.

Importantly, however, the more demanding sense of 'support' is not so demanding as to exclude non-deductive support relations like those involved in enumerative induction and inference to the best explanation. So, for example, on the intended sense of 'support',

(Past Ravens) In the past, all ravens have been black.

\section{supports}

(Next Raven) The next raven will be black.

What is excluded by the more demanding sense of 'support' are those alleged support relations that, intuitively speaking, are involved in inferences that depend on some substantive background assumption. ${ }^{23}$ We trust this more demanding sense of support is familiar to philosophers. ${ }^{24}$

What we have said so far might suggest that we think that support is a two-place relation between one proposition, or set of propositions, and another. But this is not the case. While we do think that whether one proposition supports another is independent of what any person is entitled to believe, we think that support between propositions is always relative to a set of background propositions. So, for example, while (Past Ravens) supports (Next Raven) relative to some sets of background propositions, including the empty set, it fails to support (Next Raven) relative to others. Consider, for example, the proposition that

(Genetic Experiment) The next raven will be the result of a genetic experiment that will manipulate the genes responsible for its color.

\footnotetext{
${ }^{23}$ By including the support relations involved in enumerative induction and inference to best explanation as genuine support relations, we part ways most notably with subjective Bayesians who would countenance only purely deductive relations as genuine support relations in our sense. See inter alia de Finetti (1937).

${ }^{24}$ Our discussion here is a bit too quick. According to $\mathrm{E}_{\text {SuPPORT }}$, what matters for genealogical defeat is not whether the facts that one is entitled to believe explain one's belief in fact support-in the sense described here-one's belief. What matters, rather, is whether one is entitled to believe that the facts that explain one's belief support one's belief. Hence, since one might (we think) be entitled to believe that the fact that p supports one's belief that q, even though, in fact, the fact that p does not support one's belief that q, one might be entitled to believe, say, that (Proton) supports (Streak) even though, in fact, it does not. In such cases, $\mathrm{E}_{\text {SUPPORT }}$ would not yield a verdict of defeat, which we take to be the right result. We thank an anonymous referee for encouraging us to discuss this issue.
} 
Relative to (Genetic Experiment), (Past Ravens) does not support (Next Raven). Crucially, the claim here is not that (Genetic Experiment) and (Past Ravens) together fail to support (Next Raven). Rather, the claim is that, relative to (Genetic Experiment), (Past Ravens) does not support (Next Raven).

The notion of support relative to a set of background propositions is necessary for understanding how $\mathrm{E}_{\text {SUPPORT }}$ handles NAMIBIA. Above, we claimed that $\mathrm{E}_{\text {SUPPORT }}$ delivers the correct verdict in NAMIBIA. But it may not initially be clear how this could be, since there are facts in the explanation of Nysha's belief that $d o$ support her belief, namely:

(Past-Book-Reliability) In the past, when Nysha has read a book labeled 'non-fiction' thathas said $p$, it has been the case that $p$.

(This-Book-Says) This book labeled 'non-fiction' says that there are monarchs in Namibia.

These two facts are part of the explanation of why Nysha now believes that there are monarchs in Namibia. But these facts (inductively) support Nysha's belief that there are monarchs in Namibia. ${ }^{25}$ If so-or rather, if Nysha is entitled to believe that this is so-then doesn't $\mathrm{E}_{\text {SuPPORT }}$ fail to deliver the correct verdict about NAMIBIA after all? ${ }^{26}$

The solution to this problem is to note that although (Past-Book-Reliability) and (This-BookSays) support Nysha's belief relative to many possible sets of background propositions, including the empty set, they do support her belief relative to the full set of background propositions she ought to believe, which of course includes the proposition that

(Author-Fabrication) When the author of this book wrote that there are monarchs inNamibia, he was just making stuff up.

Let us say that the fact that $\mathrm{p}$ supports* S's belief that $\mathrm{q}$ if and only if the fact that $\mathrm{p}$ supports, relative to everything else S ought to take to be the case, S's belief that q. We can replace 'support' with 'support*' to get

\section{( $E_{\text {SUPPORT }^{*}}$ ) If $S$ is not entitled to believe that the facts that explain her belief that psupport* her belief that $\mathbf{p}$, then S's belief that $\mathrm{p}$ is defeated.}

\section{$\mathrm{E}_{\text {SUPPORT* }}$ delivers the correct verdict in NAMIBIA.}

One might worry that $\mathrm{E}_{\text {SUPPORT* }}$ is a "trivial" account of genealogical defeat in the following sense. We started with this question: why does learning that this author was just making stuff up defeat Nysha's belief? The answer that $\mathrm{E}_{\text {SupporT* }}$ offers simply assumes that (Past-BookReliability) and (This-Book-Says) do not support, relative to (Author-Fabrication), Nysha's belief that there are monarchs in Namibia-or, at rate, that Nysha isn't entitled to think that they do. One might insist that insofar as one has given no account of why the former propositions don't support Nysha's belief relative to the latter, one has simply assumed what was to be accounted for.

While we have some sympathy for this objection, we think it understates the substance of $\mathrm{E}_{\text {SUPPORT* }}$. While it is true that the account, as we have developed it, takes for granted certain claims

\footnotetext{
${ }^{25}$ We do not claim that whenever someone believes on the basis of testimony, they reason by induction (see Lackey 2006). But we do claim that in the explanatory history of beliefs formed on the basis of testimony, there will often be facts that form an inductive basis for the belief so-formed.

${ }^{26}$ We are grateful to Daniel Story and Seyed Yarandi for pressing us on this point.
} 
about which facts support a given belief, relative to which other facts, this does not trivialize the account. The account is substantive in that it makes the substantive claim that genealogical defeat is a matter of what the believer is entitled to believe about the relationships of support between the facts that explain her belief and the belief itself. Such a claim is far from trivial. Moreover, we think this 'passing of the buck' from questions about genealogical defeat to questions about relations of support is exactly what one ought to expect. It would be surprising if the conditions of genealogical defeat weren't determined by support relationships: such a view would deliver an uncomfortably disunified epistemology.

\section{7 | TREATING FACTS AS REASONS}

We take $\mathrm{E}_{\text {SUPPORT* }}$ to be a plausible account of genealogical defeat. Nevertheless, it is unsatisfactory as it now stands, insofar as it mishandles cases like the following.

\section{SWITCHES}

Sonya finds herself in an illuminated room. She's not sure if the overhead lights are on or if the room is being lit by the Sun through an open skylight. She looks at the wall and sees two switches. One is labeled 'lights' and is in the 'on' position. The other is labeled 'skylight' and is in the 'closed' position. Because she sees the switches in these positions, she believes that the lights are on and that the skylight is closed. She then learns, however, that these switches control the lights and skylight in some other room, and that the state of the lights and skylight in her room has nothing to do with these switches. Sonya nevertheless continues to believe that the lights are on in her room.

SWITCHES is a rather straightforward case of genealogical defeat. But $\mathrm{E}_{\text {SUPPORT* }}$ cannot capture this case. From Sonya's (pre-defeated) point of view, the fact that the lights are on explains her being able to see the switches, and hence explains why she believes that the lights are on. Moreover, since the fact that the lights are on entails the content of Sonya's belief, and since deductive support is monotonic, that fact will support her belief relative to anything else she might take to be the case. Thus, as far as $\mathrm{E}_{\text {SuPPORT* }}$ is concerned, Sonya's belief is in good standing. But her belief has clearly been genealogically defeated. So $\mathrm{E}_{\mathrm{SUPPORT}^{*}}$ is at best an incomplete account of genealogical defeat.

We think that $\mathrm{E}_{\text {SuPPORT* }}$ mishandles this case because it is insensitive to a distinction between two different kinds of roles facts can play in the explanation of a belief: (i) being treated as reasons for belief and (ii) merely facilitating treating some other fact as a reason. To illustrate the distinction, consider the following, completely commonplace scenario.

\section{BoOK}

You see a book in front of you and so believe there is a book in front of you. You are able to see this book because the lights in the room are on, and you know this is why you are able to see the book.

In BooK, both the presence of the book and the lights' being on are part of the explanation of why you come to believe that there is a book in front of you. But these two facts play epistemically 
different roles. In coming to believe that there is a book, you treat the fact that there is a book as a reason to believe there is a book. ${ }^{27}$ But you do not treat the fact that the lights are on as a reason to believe that there is a book. Rather, the lights' being on facilitates your seeing the book, and hence facilitates your treating the fact that there is a book as a reason to believe that there is a book. $^{28}$

Some may worry that by invoking the notion of treating a fact as a reason, we are overintellectualizing the belief-forming process. However, treating a fact as a reason, as we understand it, does not require consciously conceptualizing that fact as a reason, or consciously conceptualizing that fact at all. When you treat the fact that there is a book in front of you as a reason to believe there is a book in front of you, you typically do so automatically and unconsciously. During a global pandemic, handwashing might become so routine that you treat the fact that you have just returned home as a reason to wash your hands, even though you never consciously thought about the fact that you have just returned home. Similarly, when reviewing job applicants, you mightinappropriately, and against your better judgment-treat the fact that someone has a "foreignsounding name" as a reason to not hire them, even though you never consciously thought about whether their name was foreign-sounding, let alone thought about whether this was a reason not to hire them.

Moreover, you need not be, so to speak, "directly" aware of a fact in order to treat it as a reason. Suppose your friend tells you that Mike left the office ten minutes ago. You might then treat the fact that Mike left the office ten minutes ago as a reason to believe that he will be home soon. Although you are only indirectly aware-via your friend's testimony—that Mike left the office ten minutes ago, you can still treat that fact as a reason.

With the notion of treating a fact as a reason in hand, we offer the following improvement on $\mathrm{E}_{\text {SUPPORT* }}$ :

\section{( $\mathrm{E}_{\mathrm{SUPPORT}^{* *}}$ ) If $\mathrm{S}$ is not entitled to believe that of the facts that explain her belief that p,those she treats as reasons to believe that p support* her belief that $\mathbf{p}$,then S's belief that $p$ is defeated.}

Unlike $\mathrm{E}_{\mathrm{SUPPORT}^{*}}, \mathrm{E}_{\mathrm{SUPPORT}^{* *}}$ gets the right result in SwITCHES. It's true that, from Sonya's perspective, the fact that the lights are on is part of what explains her belief that the lights are on, because it facilitates her seeing the switch. But she does not, even from her own perspective, treat the fact that the lights are on as a reason to believe that the lights are on (as she might if she had looked up to see the source of the light). Rather, she treats the fact that the switch is in the 'on' position (together with certain past facts about switches and what they control) as her reason to believe that the lights are on. But these facts do not support, relative to that which she now ought to take to be the case (e.g., that this switch does not control the lights in this room), her belief that the lights are on-and Sonya is not entitled to believe that they do. Accordingly, $\mathrm{E}_{\mathrm{SUPPORT}^{* *}}$ implies that her belief has been defeated. This is the correct result.

$\mathrm{E}_{\text {SUPPORT** }}$ also delivers the correct verdicts in SUNRISE and NAMIBIA. In SUNRISE, Sonny treats facts about past sunrises as reasons for believing that the Sun will rise tomorrow. And he knows-or at least is entitled to believe-that these facts support* his belief that the Sun will rise

\footnotetext{
${ }^{27}$ We assume, in agreement with Hyman (1999, 2011) and Hornsby (2007), and pace Dancy (2000, 2011), that external-world facts can be treated as reasons.

${ }^{28}$ See Locke (2015) for further discussion of this distinction. See Dancy (2004) on 'favourers' and 'enablers' for a related but distinct distinction.
} 
tomorrow. Hence, Sonny's belief is in good standing as far as $\mathrm{E}_{\text {SUPPORT }^{* *}}$ is concerned. In NAMIBIA, Nysha treats the fact that the book says there are monarchs in Namibia as her reason for believing that this is so. But relative to the fact that the author was just making stuff up, the fact she treats as a reason does not support her belief that there are monarchs in Namibia. Since Nysha knows this-or at least ought to- $\mathrm{E}_{\text {SUPPORT** }^{* *}}$ implies that her belief has been defeated, which it has. $^{29}$

\section{8 | THE ULTIMATE PROPOSAL}

We believe that $\mathrm{E}_{\mathrm{SuPPORT}}{ }^{*}$ adequately handles all of the cases we have thus far considered. However, we suspect that it is needlessly complicated. In particular, we wish to consider whether the following simplified principle could do the job equally well:

\section{( $E_{\text {REASONS }}$ ) If $S$ is not entitled to believe that the facts she treats as reasons to believethat $\mathbf{p}$} support* her belief that $\mathbf{p}$, then S's belief that $\mathrm{p}$ is defeated.

$\mathrm{E}_{\text {REASONS }}$ drops the reference to facts that explain her belief that $p$. Nevertheless, it delivers the same correct verdicts as $\mathrm{E}_{\text {SUPPORT }^{* *}}$ in all of the aforementioned cases. It implies defeat in NAMIBIA because Nysha is not entitled to think that the fact she treats as a reason for her belief that there are monarchs in Namibia-namely, the fact that the book says so-supports* that belief. It implies defeat in SwITCHEs because Sonya is not entitled to think that the fact she treats as a reason for believing the lights are on-namely, that the switch is in the 'on' position-supports* that belief. Finally, it does not imply defeat in SUNRISE, since Sonny is entitled to believe that the facts he treats as reasons for believing the Sun will rise tomorrow-namely, facts about past sunrisessupport* that belief.

Moreover, despite the lack of any explicit reference to explanation, $\mathrm{E}_{\mathrm{REASONS}}$ still arguably ought to be regarded as an explanationist account of genealogical defeat. That's because treating a fact as a reason is itself an explanatory relation: one treats the fact that $\mathrm{p}$ as a reason to believe that $\mathrm{q}$ only if the fact that $\mathrm{p}$ is among the facts that explain one's belief that $\mathrm{q} .{ }^{30}$ After all, to treat a fact as a reason is to respond to that fact in a certain way, and one is not responding to a particular fact unless that fact is part of what explains one's so responding. Let's call this thesis TREC, for Treating Requires an Explanatory Connection.

(TREC) If the fact that $\mathrm{p}$ is not part of what explains $\mathrm{S}$ 's belief that $\mathrm{q}$, then $\mathrm{S}$ does not treat the fact that $\mathrm{p}$ as a reason to believe that $\mathrm{q}$.

\footnotetext{
${ }^{29} \mathrm{E}_{\text {SUPPORT }^{* *}}$ has important implications for Steiner's (1973: 60-61) response to the Benacerraf problem. According to Steiner, the axioms of number theory are part of every physical theory and therefore figure in the explanation of all physical phenomena, including all of our beliefs. But even granting that, from our pre-defeated perspective, the truths of mathematics played some role in our coming to have the mathematical beliefs that we have, this does not ensure that we treat the mathematical facts as reasons to have the mathematical beliefs that we have. So, as far as $\mathrm{E}_{\mathrm{SuPPORT}^{* *}}$ is concerned, the envisaged response is not by itself sufficient to escape the Benacerraf problem, construed as a problem of genealogical defeat (see Thurow 2013) underwritten by $\mathrm{E}_{\text {SUPPORT }^{* *} \text {. }}$

${ }^{30}$ That said, if we are wrong to think that treating a fact as a reason is an explanatory relation, then $\mathrm{E}_{\text {REAsons }}$ isn't an explanationist principle after all.
} 
One of us has argued for TREC elsewhere (see Locke 2015), and while we do not have space to rehearse the full argument here, consideration of a few cases will hopefully suffice to demonstrate its plausibility. ${ }^{31}$

\section{ICE HONESTY}

Wondering whether there will be ice on the pond, Edmund has just asked his mother what the temperature dropped to last night. His mother, having just watched the morning news, tells him that it dropped to well below freezing, which is what the meteorologist reported. On the basis of his mother's testimony, Edmund believes that it dropped to well below freezing last night, and therefore believes that there is ice on the pond.

Here it seems that, in forming his belief that there is ice on the pond, Edmund is responding, via his mother's testimony, to the fact that the temperature dropped to well below freezing last night. More specifically, it seems that Edmund is responding to that fact in a way that constitutes treating that fact as a reason. Now compare ICE HONESTY with

\section{ICE DECEPTION}

Wondering whether there will be ice on the pond, Edmund has just asked his mother what the temperature dropped to last night. On the basis of nothing other than a hunch, Edmund's mother (mistakenly) believes that the temperature stayed well above freezing. But she wants to deceive Edmund, and so she tells him that the temperature dropped to well below freezing. Now, in fact it did drop to well below freezing; what Edmund's mother tells him is, unbeknownst to her, true. On the basis of his mother's testimony, Edmund believes that it dropped to well below freezing last night, and therefore that there is ice on the pond.

Here it seems that, in forming his belief that there is ice on the pond, Edmund is not responding to the fact that the temperature dropped to well below freezing last night, and so Edmund cannot be treating that fact-although it is indeed a fact-as a reason to believe as he does. To be sure, Edmund forms his belief that there is ice on the pond on the basis of his belief that the temperature dropped to well below freezing. But, as this case illustrates, believing that $\mathrm{p}$ on the basis of a belief that $\mathrm{q}$ is not the same as treating the fact that $\mathrm{q}$ as a reason to believe that $\mathrm{p} .^{32}$

Drawing on cases like these, Unger (1975), Hyman (1999), and Hornsby (2007) have argued that one does not treat the fact that $\mathrm{p}$ as a reason to $\Phi$ unless one knows that $\mathrm{p}$. We believe that this is the wrong lesson to draw. The right lesson is that one does not treat the fact that $\mathrm{p}$ as a reason to $\Phi$ unless the fact that $\mathrm{p}$ is part of what explains one's $\Phi$-ing. Again, we do not have space to rehearse

\footnotetext{
31 The first two cases that follow are adapted from Hornsby (2007). Similar cases can be found in Unger (1975) and Hyman (1999).

${ }^{32}$ Complicating matters here is a certain ambiguity in the phrase 'S's reason for $\Phi$-ing is that p'. The case where (1) $S$ treats the fact that $p$ as a reason to $\Phi$ and the case where (2) $S \Phi$ 's on the basis of her belief that $p$, can both fairly be described as cases where (one of) S's reasons for $\Phi$-ing is that $p$. See Hyman (2011) and Locke (2015) for a defense of this ambiguity thesis. See Dancy (2011) for an opposing view.
} 
the full argument here, but one can get a sense of what is wrong with the Hornsby/Unger/Hyman diagnosis by considering a case modeled after Goldman's famous ‘fake-barn' Gettier case.

\title{
FAKE-MOTHER INVASION
}

\begin{abstract}
Wondering whether there will be ice on the pond, Edmund has just asked (someone who appears to be) his mother what the temperature dropped to last night. However, unbeknownst to Edmund, his home has just been invaded by aliens disguised as perfect duplicates of his mother. If Edmund had spoken with any one of these aliens, thinking it was his mother, he would have been told that the temperature stayed well above freezing. But, by nothing other than an extraordinary coincidence, Edmund is talking to his actual mother. Having just watched the morning news, she tells him that it dropped to well below freezing, which is what the meteorologist reported. On the basis of his mother's testimony, Edmund believes that it dropped to well below freezing last night, and therefore believes that there is ice on the pond.
\end{abstract}

In FAKE-MOTHER INVASION, Edmund does not know that the temperature dropped to well below freezing last night. Nonetheless, it seems that Edmund is responding, via his mother's testimony, to the fact that it dropped to well below freezing last night, and is responding in a way that constitutes treating that fact as a reason. Cases like this suggest that what's going on in ICE DECEPTIONwhat's preventing Edmund, in that case, from treating the fact that it dropped to well below freezing as a reason-is that Edmund is, so to speak, "explanatorily disconnected" from that fact. When, in FAKE-MOTHER INVASION, we add in the explanatory connection, but leave out the knowledge, it seems that Edmund is now able to treat the fact as a reason.

For the reasons just given, we think TREC is quite plausible. And if TREC is true-that is, if treating a fact as a reason requires an explanatory connection to that fact-then we think $\mathrm{E}_{\text {REAsons }}$ should be regarded as a version of explanationism.

Nevertheless, there is a crucial difference between $\mathrm{E}_{\text {REASONS }}$ and the explanationist accounts that preceded it, which can be brought out by considering cases in which one is entitled to (mistakenly) reject TREC itself. One might, for instance, have been convinced by a misleading but seemingly cogent argument that treating a fact as a reason does not require responding to that fact, or that responding to a fact does not require the fact to explain one's so responding. Alternatively, one might simply have a strong intuition that TREC is false. Such a person might be entitled to believe that they are treating the fact that $\mathrm{p}$ as a reason to believe that $\mathrm{q}$ even though they are not entitled to believe that the fact that $\mathrm{p}$ is among the facts that explain their believing that q. For such a person, whether their belief has been defeated, according to $\mathrm{E}_{\text {REAsons }}$, will not be a matter of which facts they are entitled to believe are among the facts that explain their belief.

To make this concrete, let's consider a variation on NAMIBIA. Maya, like Nysha, believes that there are monarchs in Namibia because it said so in a book she read. Like Nysha, Maya discovers that the author was making stuff up and thereby loses entitlement to believe that any of the facts that explain her belief that there are monarchs in Namibia support* that belief. By her lights, the fact that there are monarchs (which does support* the belief) doesn't explain her belief that there are, and the fact that the book says so (which explains her belief) doesn't support* her belief. Suppose, however, that Maya, unlike Nysha, is entitled to (mistakenly) reject TREC. Suppose, moreover, that despite the explanatory revelation, Maya is entitled (by anti-TREC arguments or intuitions) to believe that she treats the fact that there are monarchs in Namibia as a reason to believe that there are. In our view, Maya has something of a "magical" view about treating facts as 
reasons: she thinks she can respond to, and thus treat those facts as reasons, even when those facts are not explanatorily upstream, so to speak, from her attitudes. Nonetheless, she is, by assumption, entitled to believe that she is treating the monarch fact as a reason for her monarch belief, and she can see that this fact straightforwardly supports* her belief. Accordingly, as far as $\mathrm{E}_{\text {ReAsons }}$ is concerned, Maya's belief is undefeated.

One may protest that it surely must be possible to use the information about the book's origins to debunk Maya's monarch beliefs. We agree. However, given Maya's unusual antecedent philosophical views, a successful debunking argument based on this information must be supplemented with an argument for TREC. There should be no surprise here: principles of genealogical defeat tell you what conditions must be met for defeat to occur, but not that those conditions are met in any given case. Accordingly, the need for this sort of supplementation potentially arises for any debunking argument underwritten by a principle of genealogical defeat. After all, there could be a Daya who, by dint of argument or intuition, winds up entitled to believe that what the book says supports her belief that there are monarchs in Namibia even relative to the belief that it was all made up. And there could be a Mischa who winds up entitled to believe that the fact that there are monarchs in Namibia manages to non-causally influence the contents of the book. ${ }^{33}$ These unusual characters first need to be argued out of their unusual views of support and explanation (respectively) before the genealogical information can defeat their monarch beliefs. $^{34}$

Finally, one might wonder whether our ultimate account, $\mathrm{E}_{\text {ReAsons, }}$, is trivial. Looked at one way, it is simply saying what everyone already believes, namely that one's reasons have to be good reasons. But $\mathrm{E}_{\text {REASONS }}$ says far more than just this. $\mathrm{E}_{\text {REASONS }}$ tells us when and why explanatory revelations can defeat, and highlights the "dual epistemic upshots" of explanatory revelations. The first upshot of explanatory revelations concerns whether the facts one is entitled to believe one treats as reasons for believing support* one in so believing. The second upshot concerns which facts one is entitled to believe one is or is not treating as a reason. Should you learn that you are in the Matrix you lose your entitlement to believe that the fact that you appear to have hands supports* your belief that you have hands and, additionally, lose your entitlement to believe that you are, or ever were, treating the fact that you have hands as a reason for believing that you have hands. These two epistemic upshots work in concert to ensure that, from your perspective, your belief that you have hands has been defeated.

\section{9 | CONCLUSION}

We hope to have shown that the explanationist approach to genealogical defeat is worth taking seriously, and that preliminary difficulties with inductive beliefs are by no means insurmountable. Moreover, we hope to have shown that the best version of explanationism is one that is couched in terms of the facts that support one's beliefs and is sensitive to the distinction between those facts that merely form some part of the explanation of why one believes as one does and those more specific facts that one treats as a reason to believe as one does.

\footnotetext{
${ }^{33}$ Think also of moral debunking arguments which, depending on one's interlocutor, may need to be supplemented by an argument that nonnatural moral facts do not figure in evolutionary explanations, or that they do not figure in "constitutive" explanations of our moral beliefs.

${ }^{34}$ Those who still feel that Maya is defeated, despite her unusual views about treating-as-reasons, may always retreat to $\mathrm{E}_{\text {SUPPORT** }}$
} 


\section{REFERENCES}

Bedke, M. S. (2009). Intuitive Non-Naturalism Meets Cosmic Coincidence. Pacific Philosophical Quarterly, 90, 188209.

Bedke, M. S. (2014). No Coincidence? Oxford Studies in Metaethics, 9, 102-125.

Bengson, J. (2015). Grasping the Third Realm. Oxford Studies in Epistemology, 5, 1-38.

Bergmann, M. (2005). Defeaters and Higher-Level Requirements. Philosophical Quarterly, 55, 419-436.

Berry, S. E. (2020). Coincidence Avoidance and Formulating the Access Problem. Canadian Journal of Philosophy, 50, 687-701.

Bogardus, T. and Perrin, W. Forthcoming. Knowledge is Believing Something Because It's True. Episteme.

Braddock, M. (2017). Debunking Arguments from Insensitivity. International Journal for the Study of Skepticism, 7, 91-113.

Clarke-Doane, J. (2015). Justification and Explanation in Mathematics and Morality. Oxford Studies in Metaethics, $10,80-103$.

Clarke-Doane, J. (2016). Debunking and Dispensability. In N. Sinclair \& U. Leibowitz (Eds.), Explanation in Ethics and Mathematics (pp. 23-36). Oxford: Oxford University Press.

Clarke-Doane, J. (2020). Morality and Mathematics. Oxford: Oxford University Press.

Clarke-Doane, J. and Baras, D. (2021). Modal Security. Philosophy and Phenomenological Research, 102, 162-183.

Dancy, J. (2000). Practical Reality. Oxford: Oxford University Press.

Dancy, J. (2004). Ethics without Principles. Oxford: Oxford University Press

Dancy, J. (2011). Acting in Ignorance. Frontiers of Philosophy in China, 6, 345-357.

de Finetti, B. (1937). La Prévision: Ses Lois Logiques, Se Sources Subjectives. Annales de l'Institut Henri Poincaré, 7, 1-68; Translated into English and reprinted in Kyburg and Smokler (1980).

Enoch, D. (2010). The Epistemological Challenge to Metanormative Realism. Philosophical Studies, 148, 413-438.

Faraci, D. (2019). Groundwork for an Explanationist Account of Epistemic Coincidence. Philosophers' Imprint, 19, $1-26$.

Goldman, A. I. (1967). A Causal Theory of Knowing. The Journal of Philosophy, 64, 357-372.

Harman, G. (1973). Thought. Princeton: Princeton University Press.

Hornsby, J. (2007). Knowledge, Belief, and Reasons for Acting. In C. Penco, M. Beaney, \& M. Vignolo (Eds.), Explaining the Mental: Naturalist and Non-Naturalist Approaches to Mental Acts and Processes (pp. 88-105). Newcastle, UK: Cambridge Scholars Publishing.

Hyman, J. (1999). How Knowledge Works. Philosophical Quarterly, 49, 433-451.

Hyman, J. (2011). Acting for Reasons: Reply to Dancy. Frontiers of Philosophy in China, 6, 358-368.

Killoren, D. (2021). An Occasionalist Response to Korman and Locke. Journal of Ethics and Social Philosophy, 19, 311-323.

Kyburg H. E. and Smokler H. E. (1980). Studies in Subjective Probability. Huntington, NY: Krieger.

Korman, D. Z. (2019a). Debunking Arguments. Philosophy Compass, 14, 1-17.

Korman, D. Z. (2019b). Debunking Arguments in Metaphysics and Metaethics. In B. McLaughlin \& A. I. Goldman (Eds.), Cognitive Science and Metaphysics (pp. 337-363). Oxford: Oxford University Press.

Korman, D. Z. and Locke, D. (2020). Against Minimalist Responses to Moral Debunking Arguments. Oxford Studies in Metaethics, 15, 309-332.

Lackey, J. (2006). It Takes Two to Tango: Beyond Reductionism and Non-Reductionism in the Epistemology of Testimony. In J. Lackey \& E. Sosa (Eds.), The Epistemology of Testimony (pp. 160-189). Oxford: Oxford University Press.

Lipton, P. (1990). Contrastive Explanation. Royal Institute of Philosophy Supplement, 27, 247-266.

Livengood, J. and Korman, D. Z. (2020). Debunking Material Induction. Studies in the History and Philosophy of Science Part A, 84, 20-27.

Locke, D. (2015). Knowledge, Explanation, and Motivating Reasons. American Philosophical Quarterly, 52, 215-232.

Lutz, M. (2018). What Makes Evolution a Defeater? Erkenntnis, 83, 1105-1126.

Lutz, M. (2020). The Reliability Challenge in Moral Epistemology. Oxford Studies in Metaethics, 15, 280-303.

Pryor, J. (2004). What's Wrong With Moore's Argument? Philosophical Perspectives, 14, 349-378.

Pust, J. (2001). Against Explanationist Skepticism. Philosophical Studies, 106, 227-258.

Setiya, K. (2012). Knowing Right from Wrong. Oxford: Oxford University Press. 
Steiner, M. (1973). Platonism and the Causal Theory of Knowledge. The Journal of Philosophy, 70, 57-66.

Thurow, J. C. (2013). The Defeater Version of Benacerraf's Problem for A Priori Knowledge. Synthese, 190, 15871603.

Topey, B. Forthcoming. Realism, Reliability, and Epistemic Possibility: On Modally Interpreting the BenacerrafField Challenge. Synthese.

Unger, P. (1975). Ignorance: A Case for Skepticism. Oxford: Oxford University Press.

Vavova, K. (2015). Evolutionary Debunking of Moral Realism. Philosophy Compass, 10, 104-116.

Warren, J. (2017). Epistemology versus Non-Causal Realism. Synthese, 194, 1643-1662.

How to cite this article: Korman, D. Z., Locke, D.. An Explanationist Account of Genealogical Defeat. Philosophy and Phenomenological Research. 2021;1-20. https://doi.org/10.1111/phpr.12848 